\title{
Optimal Control of a Delayed HIV Infection Model with Immune Response Using an Efficient Numerical Method
}

\author{
Khalid Hattaf and Noura Yousfi \\ Department of Mathematics and Computer Science, Faculty of Sciences Ben M'sik, Hassan II University, P.O. Box 7955, \\ Sidi Othman, Casablanca, Morocco \\ Correspondence should be addressed to Khalid Hattaf, k.hattaf@yahoo.fr and Noura Yousfi, nourayousfi@gmail.com
}

Received 26 August 2012; Accepted 30 October 2012

Academic Editors: R. P. Bahadur and M. A. Panteleev

Copyright (๑) 2012 K. Hattaf and N. Yousfi. This is an open access article distributed under the Creative Commons Attribution License, which permits unrestricted use, distribution, and reproduction in any medium, provided the original work is properly cited.

\begin{abstract}
We present a delay-differential equation model with optimal control that describes the interactions between human immunodeficiency virus (HIV), CD4 ${ }^{+} \mathrm{T}$ cells, and cell-mediated immune response. Both the treatment and the intracellular delay are incorporated into the model in order to improve therapies to cure HIV infection. The optimal controls represent the efficiency of drug treatment in inhibiting viral production and preventing new infections. Existence for the optimal control pair is established, Pontryagin's maximum principle is used to characterize these optimal controls, and the optimality system is derived. For the numerical simulation, we propose a new algorithm based on the forward and backward difference approximation.
\end{abstract}

\section{Introduction}

Human immunodeficiency virus (HIV) is a lentivirus that causes acquired immunodeficiency syndrome (AIDS), a condition in humans in which the immune system begins to fail, leading to life-threatening opportunistic infections. There are several other ways the infection can transfer, for example, open wound, saliva, and ulcers.

There are some antiretroviral (ARV) drugs available nowadays which help the immune system in preventing the infection due to HIV even though it is not possible to cure it. Reverse transcriptase inhibitors (RTIs) are one of the chemotherapies which oppose the conversion of RNA of the virus to DNA (reverse transcription), so that the viral population will be minimum and on the other hand the CD4 ${ }^{+}$ count remains higher and the host can survive. Another one is the protease inhibitors (PIs) which prevent the production of viruses from the actively infected $\mathrm{CD} 4^{+} \mathrm{T}$ cells.

In the literature, many mathematical models have been developed in order to understand the dynamics of HIV infection [1-6]. In addition, optimal control methods have been applied to the derivation of optimal therapies for this HIV infection [7-13]. All these methods are based on HIV models which ignore the intracellular delay by assuming that the infectious process is instantaneous; that is, in the very moment that the virus enters an uninfected cell, this one starts to produce virus particles, and we know that this is not biologically reasonable. In this paper, we consider the mathematical model for HIV infection with intracellular delay and cell-mediated immune response presented by Zhu and Zou in [6] and we introduce two controls, one simulating effect of RTIs and the other control simulating effect of PIs, incorporating drug efficacy. The intracellular delay represents the time needed for infected cells to produce virions after viral entry.

The paper is organized as follows. Section 2 describes a delayed mathematical model of HIV infection with two control terms. The analysis of optimization problems is presented in Section 3. In Section 4, we present a numerical appropriate method and the simulation corresponding results. Finally, the conclusions are summarized in Section 5. 


\section{HIV Model with Intracellular Delay}

We consider the mathematical model for HIV-1 infection with intracellular delay and cell-mediated immune response presented by Zhu and Zou in [6]. The dynamics of this model are governed by the following equations:

$$
\begin{gathered}
\frac{d x}{d t}=s-d x(t)-k v(t) x(t), \\
\frac{d y}{d t}=k e^{-\delta \tau} v(t-\tau) x(t-\tau)-\delta y(t)-p y(t) z(t), \\
\frac{d v}{d t}=N \delta y(t)-\mu v(t), \\
\frac{d z}{d t}=c y(t) z(t)-b z(t),
\end{gathered}
$$

where $x(t), y(t), v(t)$, and $z(t)$ denote the concentrations of uninfected cells, infected cells, and virus and cytotoxic $\mathrm{T}$ lymphocytes (CTLs), respectively.

Susceptible host cells $(x)$ are produced at a rate $s$, die at a rate $d$, and become infected by virus at a rate $k$. Infected cells die at a rate $\delta$ and are killed by the CTLs response at a rate $p$. Free virus is produced by infected cells at a rate $N \delta$ and decays at a rate $\mu$ where $N$ is the number of free virus produced by infected cells. CTLs expand in response to viral antigen derived from infected cells at a rate $c$ and decay in the absence of antigenic stimulation at a rate $b$. The intracellular delay, $\tau$, represents the time needed for infected cells to produce virions after viral entry.

We introduce two controls $u_{1}$ and $u_{2}$ which measure the efficiency of reverse transcriptase and protease inhibitors, respectively. Hence, (1) becomes

$$
\begin{gathered}
\frac{d x}{d t}=s-d x(t)-\left(1-u_{1}(t)\right) k v(t) x(t) \\
\frac{d y}{d t}=\left(1-u_{1}(t)\right) k e^{-\delta \tau} v(t-\tau) x(t-\tau)-\delta y(t)-p y(t) z(t), \\
\frac{d v}{d t}=\left(1-u_{2}(t)\right) N \delta y(t)-\mu v(t), \\
\frac{d z}{d t}=c y(t) z(t)-b z(t) .
\end{gathered}
$$

The control functions, $u_{1}(t)$ and $u_{2}(t)$, are bounded, Lebesgue integrable functions. The control $u_{2}(t)$ represents the efficiency of drug therapy in inhibiting viral production, such that the virion production rate under therapy is $(1-$ $\left.u_{2}(t)\right) N \delta$.

If $u_{2}=1$, the inhibition is $100 \%$ effective, whereas if $u_{2}=$ 0 , there is no inhibition.

The control $u_{1}(t)$ represents the efficiency of drug therapy in blocking new infection, so that infection rate in the presence of drug is $\left(1-u_{1}(t)\right) \beta$.

Let $C=C\left([-\tau, 0], \mathbb{R}^{4}\right)$ be the Banach space of continuous functions mapping the interval $[-\tau, 0]$ into $\mathbb{R}^{4}$ with the topology of uniform convergence. It is easy to show that there exists a unique solution $(x(t), y(t), v(t), z(t))$ of system (2) with initial data $\left(x_{0}, y_{0}, v_{0}, z_{0}\right) \in C$.
In addition, for biological reasons, we assume that the initial data for system (2) satisfy

$$
\begin{array}{r}
x_{0}(s) \geq 0, \quad y_{0}(s) \geq 0, \quad v_{0}(s) \geq 0, \quad z_{0}(s) \geq 0, \\
s \in[-\tau, 0] .
\end{array}
$$

\section{The Optimal Control Problems}

The problem is to maximize the objective functional

$$
J\left(u_{1}, u_{2}\right)=\int_{0}^{t_{f}}\left\{x(t)+z(t)-\left[\frac{A_{1}}{2} u_{1}^{2}(t)+\frac{A_{2}}{2} u_{2}^{2}(t)\right]\right\} d t
$$

where the parameters $A_{1} \geq 0$ and $A_{2} \geq 0$ are based on the benefits and costs of the treatment. Our target is to maximize the objective functional defined in (4) by increasing the number of the uninfected cells, maximizing immune response by CTLs, decreasing the viral load, and minimizing the cost of treatment. In other words, we are seeking optimal control pair $\left(u_{1}^{*}, u_{2}^{*}\right)$ such that

$$
J\left(u_{1}^{*}, u_{2}^{*}\right)=\max \left\{J\left(u_{1}, u_{2}\right):\left(u_{1}, u_{2}\right) \in U\right\},
$$

where $U$ is the control set defined by

$$
\begin{aligned}
& U=\left\{u=\left(u_{1}, u_{2}\right): u_{i}\right. \text { measurable, } \\
& \left.\quad 0 \leq u_{i}(t) \leq 1, t \in\left[0, t_{f}\right], i=1,2\right\} .
\end{aligned}
$$

3.1. Existence of an Optimal Control Pair. The existence of the optimal control pair can be obtained using a result by Fleming and Rishel in [14] and by Lukes in [15].

Theorem 1. There exists an optimal control pair $\left(u_{1}^{*}, u_{2}^{*}\right) \in U$ such that

$$
J\left(u_{1}^{*}, u_{2}^{*}\right)=\max _{\left(u_{1}, u_{2}\right) \in U} J\left(u_{1}, u_{2}\right) .
$$

Proof. To use an existence result in [14], we must check the following properties.

(1) The set of controls and corresponding state variables is nonempty.

(2) The control $U$ set is convex and closed.

(3) The right-hand side of the state system is bounded by a linear function in the state and control variables.

(4) The integrand of the objective functional is concave on $U$.

(5) There exists constants $c_{1}, c_{2}>0$, and $\beta>1$ such that the integrand $L\left(x, z, u_{1}, u_{2}\right)$ of the objective functional satisfies

$$
L\left(x, z, u_{1}, u_{2}\right) \leq c_{2}-c_{1}\left(\left|u_{1}\right|^{2}+\left|u_{2}\right|^{2}\right)^{\beta / 2} .
$$

In order to verify these conditions, we use a result by Lukes in [15] to give the existence of solutions of system (2) with 
bounded coefficients, which gives condition 1 . We note that the solutions are bounded. Our control set satisfies condition 2. Since our state system is bilinear in $u_{1}, u_{2}$, the righthand side of system (2) satisfies condition 3, using the boundedness of the solutions. Note that the integrand of our objective functional is concave. Also we have the last condition needed

$$
L\left(x, z, u_{1}, u_{2}\right) \leq c_{2}-c_{1}\left(\left|u_{1}\right|^{2}+\left|u_{2}\right|^{2}\right)
$$

where $c_{2}$ depends on the upper bound on $x$ and $z$, and $c_{1}>0$ since $A_{1}, A_{2}>0$. We conclude that there exists an optimal control pair.

3.2. Optimality System. Pontryagin's minimum Principle with delay given in [16] provides necessary conditions for an optimal control problem. This principle converts (2), (4), and (5) into a problem of maximizing an Hamiltonian, $H$, with

$$
\begin{aligned}
& H\left(t, x, y, v, z, x_{\tau}, v_{\tau}, u_{1}, u_{2}, \lambda\right) \\
&= \frac{A_{1}}{2} u_{1}^{2}+\frac{A_{2}}{2} u_{2}^{2}-x-z \\
&+\lambda_{1}\left[s-d x-\left(1-u_{1}\right) k v x\right] \\
&+\lambda_{2}\left[\left(1-u_{1}\right) k e^{-\delta \tau} v_{\tau} x_{\tau}-\delta y-p y z\right] \\
&+\lambda_{3}[N \delta y-\mu v]+\lambda_{4}[c y z-b z] .
\end{aligned}
$$

By applying Pontryagin's minimum principle with delay in state [16], we obtain the following theorem.

Theorem 2. Given optimal controls $u_{1}^{*}, u_{2}^{*}$, and solutions $x^{*}$, $y^{*}, v^{*}$ and $z^{*}$ of the corresponding state system (2), there exists adjoint variables, $\lambda_{1}, \lambda_{2}, \lambda_{3}$, and $\lambda_{4}$ satisfying the equations

$$
\begin{gathered}
\lambda_{1}^{\prime}(t)=1+\lambda_{1}(t)\left[d+\left(1-u_{1}^{*}(t)\right) k v^{*}(t)\right] \\
+\chi_{\left[0, t_{f}-\tau\right]}(t) \lambda_{2}(t+\tau)\left(u_{1}^{*}(t+\tau)-1\right) k e^{-\delta \tau} v^{*}(t), \\
\lambda_{2}^{\prime}(t)=\lambda_{2}(t) \delta-\lambda_{3}(t)\left(1-u_{2}^{*}(t)\right) N \delta \\
-c z^{*}(t) \lambda_{4}(t)+p z^{*}(t) \lambda_{2}(t), \\
\lambda_{3}^{\prime}(t)=\lambda_{1}(t)\left(1-u_{1}^{*}(t)\right) k x^{*}(t)+\mu \lambda_{3}(t) \\
+\chi_{\left[0, t_{f}-\tau\right]}(t) \lambda_{2}(t+\tau)\left(u_{1}^{*}(t+\tau)-1\right) k e^{-\delta \tau} x^{*}(t), \\
\lambda_{4}^{\prime}(t)=1+p y^{*}(t) \lambda_{2}(t)+\lambda_{4}(t)\left(b-c y^{*}(t)\right),
\end{gathered}
$$

with transversality conditions

$$
\lambda_{i}\left(t_{f}\right)=0, \quad i=1, \ldots, 4
$$

Moreover, the optimal control is given by

$$
\begin{array}{r}
u_{1}^{*}(t)=\min \left(1, \max \left(0, \frac{k}{A_{1}}\left[\lambda_{2}(t) e^{-\delta \tau} v^{*}(t-\tau) x^{*}(t-\tau)\right.\right.\right. \\
\left.\left.\left.-\lambda_{1}(t) v^{*}(t) x^{*}(t)\right]\right)\right) \\
u_{2}^{*}(t)=\min \left(1, \max \left(0, \frac{1}{A_{2}} \lambda_{3}(t) N \delta y^{*}(t)\right)\right)
\end{array}
$$

Proof. The adjoint equations and transversality conditions can be obtained by using Pontryagin's minimum principle with delay in state [16] such that

$$
\begin{array}{cc}
\lambda_{1}^{\prime}(t)=-\frac{\partial H}{\partial x}(t)-\chi_{\left[0, t_{f}-\tau\right]}(t) \frac{\partial H}{\partial x_{\tau}}(t+\tau), & \lambda_{1}\left(t_{f}\right)=0, \\
\lambda_{2}^{\prime}(t)=-\frac{\partial H}{\partial y}(t), \quad \lambda_{2}\left(t_{f}\right)=0, & \lambda_{3}\left(t_{f}\right)=0, \\
\lambda_{3}^{\prime}(t)=-\frac{\partial H}{\partial v}(t)-\chi_{\left[0, t_{f}-\tau\right]}(t) \frac{\partial H}{\partial v_{\tau}}(t+\tau), & \lambda_{4}\left(t_{f}\right)=0 .
\end{array}
$$

The optimal control $u_{1}^{*}$ and $u_{2}^{*}$ can be solved from the optimality conditions

$$
\frac{\partial H}{\partial u_{1}}(t)=0, \quad \frac{\partial H}{\partial u_{2}}(t)=0 .
$$

That is,

$$
\begin{gathered}
\frac{\partial H}{\partial u_{1}}(t)=A_{1} u_{1}(t)+k v(t) x(t) \lambda_{1}(t) \\
-k e^{-\delta \tau} v(t-\tau) x(t-\tau) \lambda_{2}(t)=0, \\
\frac{\partial H}{\partial u_{2}}(t)=A_{2} u_{2}(t)-N \delta y(t) \lambda_{3}(t)=0 .
\end{gathered}
$$

By the bounds in $U$ of the controls, it is easy to obtain $u_{1}^{*}$ and $u_{2}^{*}$ in the form of (13), respectively. 
If we substitute $u_{1}^{*}$ and $u_{2}^{*}$ in the systems (2) and (11), we obtain the following optimality system:

$$
\begin{aligned}
& \frac{d x^{*}}{d t}=s-d x^{*}(t)-\left(1-u_{1}^{*}(t)\right) k v^{*}(t) x^{*}(t), \\
& \frac{d y^{*}}{d t}=\left(1-u_{1}^{*}(t)\right) k e^{-\delta \tau} v^{*}(t-\tau) x^{*}(t-\tau) \\
& -\delta y^{*}(t)-p y^{*}(t) z^{*}(t), \\
& \frac{d v^{*}}{d t}=\left(1-u_{2}^{*}(t)\right) N \delta y^{*}(t)-\mu v^{*}(t), \\
& \frac{d z^{*}}{d t}=c y^{*}(t) z^{*}(t)-b z^{*}(t), \\
& \frac{d \lambda_{1}}{d t}=1+\lambda_{1}(t)\left[d+\left(1-u_{1}^{*}(t)\right) k v^{*}(t)\right] \\
& +\chi_{\left[0, t_{f}-\tau\right]}(t) \lambda_{2}(t+\tau)\left(u_{1}^{*}(t+\tau)-1\right) k e^{-\delta \tau} v^{*}(t), \\
& \frac{d \lambda_{2}}{d t}=\lambda_{2}(t) \delta-\lambda_{3}(t)\left(1-u_{2}^{*}(t)\right) N \delta \\
& -c z^{*}(t) \lambda_{4}(t)+p z\left(^{*} t\right) \lambda_{2}(t), \\
& \frac{d \lambda_{3}}{d t}=\lambda_{1}(t)\left(1-u_{1}^{*}(t)\right) k x^{*}(t)+\mu \lambda_{3}(t) \\
& +\chi_{\left[0, t_{f}-\tau\right]}(t) \lambda_{2}(t+\tau)\left(u_{1}^{*}(t+\tau)-1\right) k e^{-\delta \tau} x(t), \\
& \frac{d \lambda_{4}}{d t}=1+p y^{*}(t) \lambda_{2}(t)+\lambda_{4}(t)\left(b-c y^{*}(t)\right), \\
& u_{1}^{*}(t)=\min \left(1, \max \left(0, \frac{k}{A_{1}}\left[\lambda_{2}(t) e^{-\delta \tau} v^{*}(t-\tau) x^{*}(t-\tau)\right.\right.\right. \\
& \left.\left.\left.-\lambda_{1}(t) v^{*}(t) x^{*}(t)\right]\right)\right) \\
& u_{2}^{*}(t)=\min \left(1, \max \left(0, \frac{1}{A_{2}} \lambda_{3}(t) N \delta y^{*}(t)\right)\right), \\
& \lambda_{i}\left(t_{f}\right)=0, \quad i=1, \ldots, 4 .
\end{aligned}
$$

\section{Numerical Simulations}

In this section, we give a numerical method to solve the optimality system (17) and present the results.

Let there exists a step size $h>0$ and integers $(n, m) \in \mathbb{N}^{2}$ with $\tau=m h$ and $t_{f}-t_{0}=n h$. For reasons of programming, we consider $m$ knots to left of $t_{0}$ and right of $t_{f}$, and we obtain the following partition:

$$
\begin{gathered}
\Delta=\left(t_{-m}=-\tau<\cdots<t_{-1}<t_{0}=0<t_{1}\right. \\
\left.<\cdots<t_{n}=t_{f}<t_{n+1}<\cdots<t_{n+m}\right) .
\end{gathered}
$$

Then, we have $t_{i}=t_{0}+i h(-m \leq i \leq n+m)$. Next, we define the state and adjoint variables $x(t), y(t), v(t), z(t), \lambda_{1}(t)$, $\lambda_{2}(t), \lambda_{3}(t), \lambda_{4}(t)$ and the controls $u_{1}(t), u_{2}(t)$ in terms of nodal points $x_{i}, y_{i}, v_{i}, z_{i}, \lambda_{1}^{i}, \lambda_{2}^{i}, \lambda_{3}^{i}, u_{1}^{i}$, and $u_{2}^{i}$.

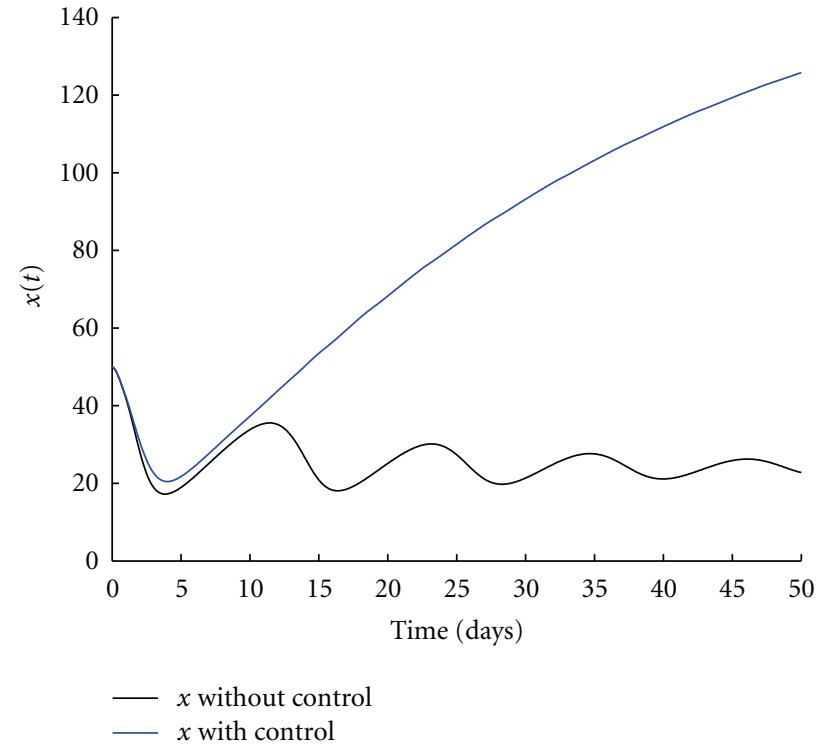

FIGURE 1: Uninfected cells $x$ with and without control.

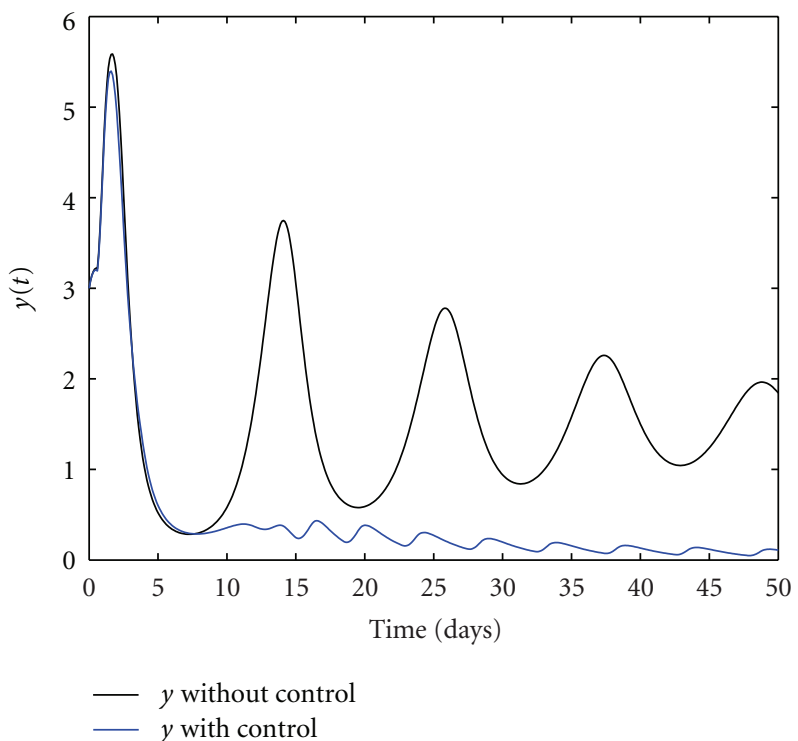

Figure 2: Infected cells $y$ with and without control.

Now a combination of forward and backward difference approximation, we obtain Algorithm 1.

For this simulation, we use the parameter values given in Table 1.

The graphs from simulating the model, given below, help to compare the uninfected cells, the infected cells, and the viral load before and after the treatments with controls.

Figure 1 shows that after the treatments, the $\mathrm{CD}^{+} \mathrm{T}$ population grows significantly which improves the quality of life of the patient.

In Figure 2, the number of infected $\mathrm{CD}^{+} \mathrm{T}$ cells at the final time $t_{f}=50$ (days) is 0.1096 in the case with control and 1.8439 without control, and the total cases in blocking new infections at the end of the control program 
TABLe 1: Parameters, their symbols and values used in simulation.

\begin{tabular}{lll}
\hline Parameters & Descriptions & Values \\
\hline$s$ & Source term for uninfected CD4 ${ }^{+}$T cells & $5 \mathrm{day}^{-1} \mathrm{~mm}^{-3}$ \\
$d$ & Death rate of CD4 ${ }^{+}$T cells & $0.03 \mathrm{day}^{-1}$ \\
$k$ & Rate CD4 T cells become infected with virus & $0.0014 \mathrm{~mm}^{3}$ virion $^{-1} \mathrm{day}^{-1}$ \\
$\delta$ & Death rate infectedCD4 ${ }^{+}$T cells & $0.32 \mathrm{day}^{-1}$ \\
$p$ & Rate at which infected cells are killed by CTLs & $0.05 \mathrm{~mm}^{3} \mathrm{day}^{-1}$ \\
$N$ & Number of free virus produced by infected cells & 480 \\
$\mu$ & Clearance rate of free virus & day $^{-1}$ \\
$b$ & Death rate of CTLs & $0.3 \mathrm{day}^{-1}$ \\
$\tau$ & Immune response activation rate & $0.2 \mathrm{~mm}^{3} \mathrm{day}^{-1}$ \\
\hline
\end{tabular}

The period of the therapy considered is 50 days.

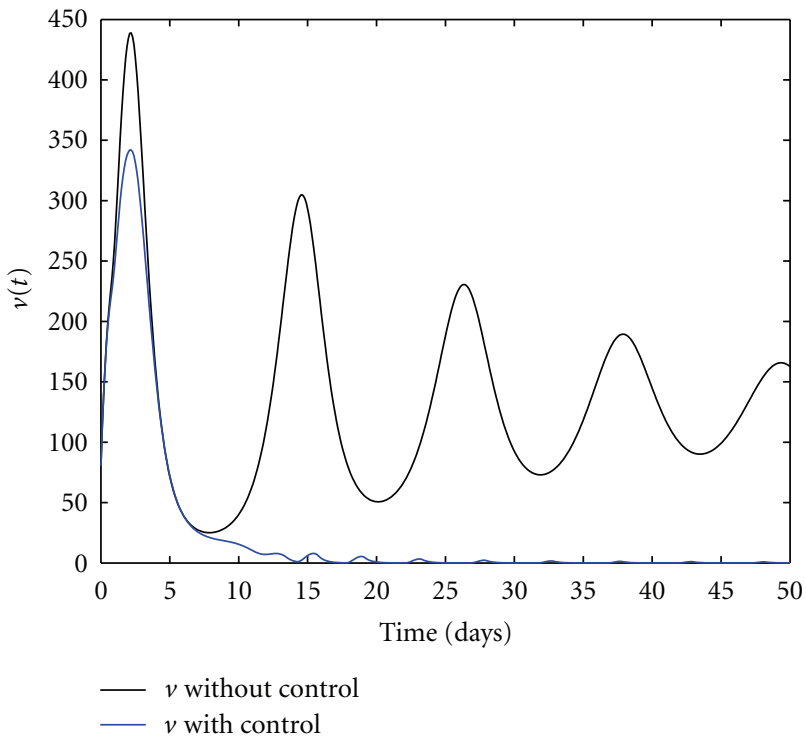

FIGURE 3: Virus $v$ with and without control.

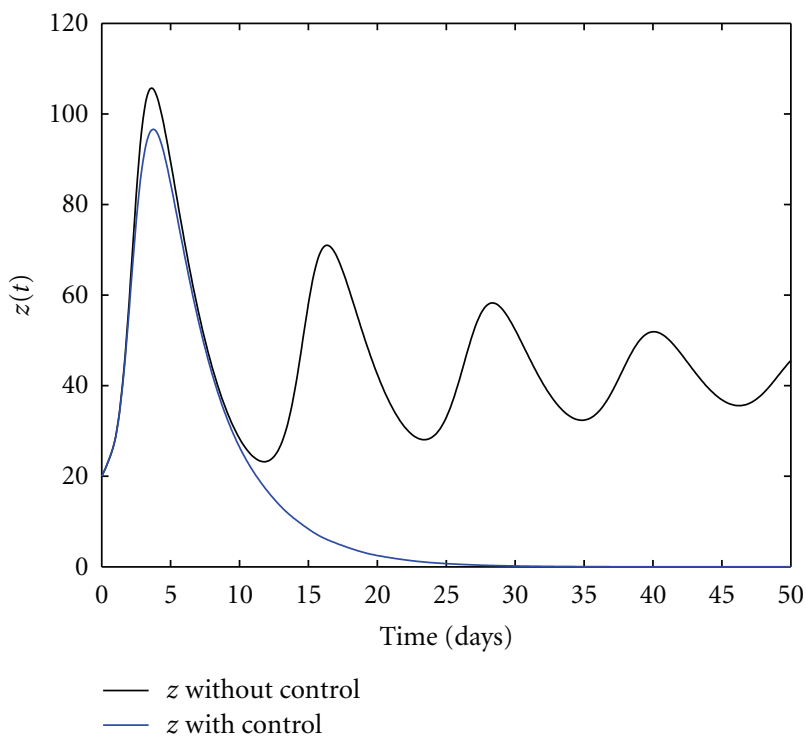

Figure 4: Function $z$ with and without control.

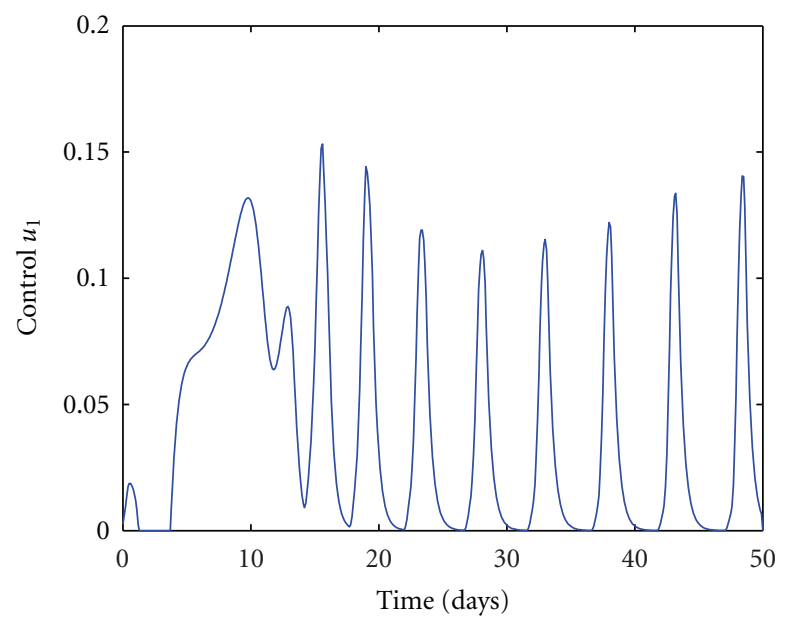

(a)

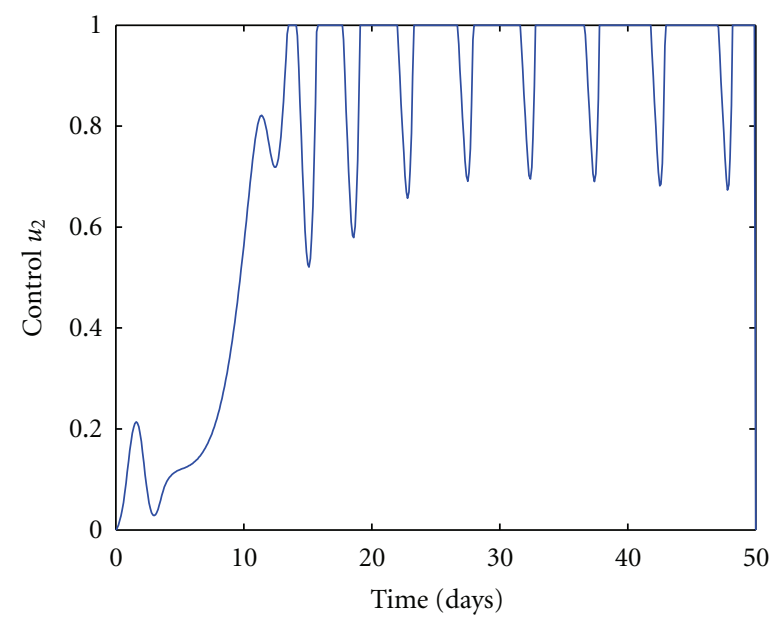

(b)

FIGURE 5: The controls $u_{1}$ and $u_{2}$.

is 1.7343 , then the efficiency of drug therapy in blocking the new infections is $94 \%$.

Figure 3 shows that after introducing therapy, the viral load declines towards zero. Specifically, the number of free 


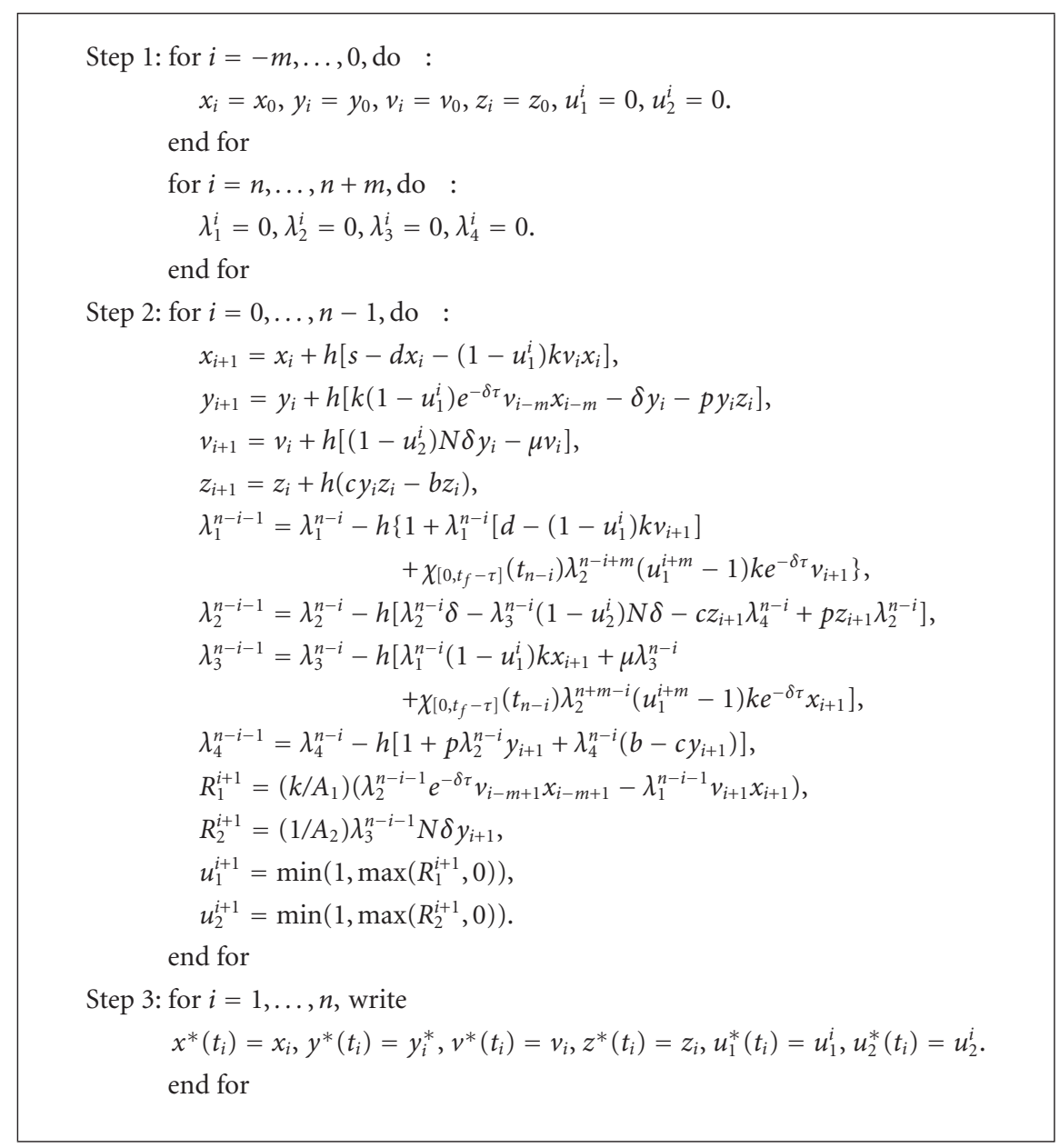

Algorithm 1

virus at the final time is 0.0250 in the case with control and 162.7342 without control, and the total cases in blocking viral production at the end of the control program is 162.7092, then the efficiency of drug therapy in inhibiting viral production is $99.98 \%$.

Figure 4 shows that the cell-mediated immune response is always maintained at a positive level and it is never eliminated. We also note that an increase in infection is followed by a corresponding increase in the immune response, which then serves to remove infection by killing off infected cells. Once the infection is low, the immune response is not needed at such high levels and this is why it drops off too. Finally, Figure 5 represents the optimal controls $u_{1}^{*}$ and $u_{2}^{*}$ in blocking new infection and inhibiting viral production.

\section{Conclusion}

The purpose of this work is two-fold. Firstly, we gave a delay mathematical model with two controls that describe HIV infection of $\mathrm{CD} 4^{+} \mathrm{T}$ cells during therapy. Currently, there is no effective therapy for HIV infection and the cost of treatment is beyond reach of many infected patients. Hence, we presented an optimal therapy in order to minimize the cost of treatment, reduce the viral load, and improve immune response. Secondly, we presented an efficient numerical method based on optimal control to identify the best treatment strategy of HIV infection in order to block new infection and prevent viral production by using drug therapy with minimum side effects.

Our numerical results show that the optimal treatment strategies reduce viral load and increase the uninfected CD $4^{+}$ T-cell count after five days of therapy.

\section{Acknowledgment}

The authors would like to thank the anonymous referee for his/her valuable comments on the first version of the paper which have led to an improvement in this revised version.

\section{References}

[1] K. Hattaf and N. Yousfi, "Dynamics of HIV infection model with therapy and cure rate," International Journal of Tomography and Statistics, vol. 16, no. 11, pp. 74-80, 2011.

[2] K. Hattaf, N. Yousfi, and A. Tridane, "Mathematical analysis of a virus dynamics model with general incidence rate and cure rate," Nonlinear Analysis: Real World Applications, vol. 13, no. 4, pp. 1866-1872, 2012. 
[3] A. S. Perelson and P. W. Nelson, "Mathematical analysis of HIV-1 dynamics in vivo," SIAM Review, vol. 41, no. 1, pp. 344, 1999.

[4] A. S. Perelson, A. U. Neumann, M. Markowitz, J. M. Leonard, and D. D. Ho, "HIV-1 dynamics in vivo: Virion clearance rate, infected cell life-span, and viral generation time," Science, vol. 271, no. 5255, pp. 1582-1586, 1996.

[5] X. Zhou, X. Song, and X. Shi, "A differential equation model of HIV infection of CD4 $4^{+}$T-cells with cure rate," Journal of Mathematical Analysis and Applications, vol. 342, no. 2, pp. 1342-1355, 2008.

[6] H. Zhu and X. Zou, "Dynamics of a HIV-1 infection model with cell-mediated immune response and intracellular delay," Discrete and Continuous Dynamical Systems, Series B, vol. 12, no. 2, pp. 511-524, 2009.

[7] K. Hattaf and N. Yousfi, "Two optimal treatments of HIV infection model," World Journal of Modelling and Simulation, vol. 8, pp. 27-36, 2012.

[8] K. R. Fister, S. Lenhart, and J. S. McNally, "Optimizing chemotherapy in an HIV model," Electronic Journal of Differential Equations, vol. 1998, pp. 1-12, 1998.

[9] H. R. Joshi, "Optimal control of an HIV immunology model," Optimal Control Applications and Methods, vol. 23, no. 4, pp. 199-213, 2002.

[10] J. Karrakchou, M. Rachik, and S. Gourari, "Optimal control and infectiology: application to an HIV/AIDS model," Applied Mathematics and Computation, vol. 177, no. 2, pp. 807-818, 2006.

[11] D. Kirschner, S. Lenhart, and S. Serbin, "Optimal control of the chemotherapy of HIV," Journal of mathematical biology, vol. 35, no. 7, pp. 775-792, 1997.

[12] H. D. Kwon, "Optimal treatment strategies derived from a HIV model with drug-resistant mutants," Applied Mathematics and Computation, vol. 188, no. 2, pp. 1193-1204, 2007.

[13] R. V. Culshaw, S. Ruan, and R. J. Spiteri, "Optimal HIV treatment by maximising immune response," Journal of Mathematical Biology, vol. 48, no. 5, pp. 545-562, 2004.

[14] W. H. Fleming and R. W. Rishel, Deterministic and Stochastic Optimal Control, Springer, New York, NY, USA, 1975.

[15] D. L. Lukes, Differential Equations: Classical To Controlled, vol. 162 of Mathematics in Science and Engineering, Academic Press, New York, NY, USA, 1982.

[16] L. Göllmann, D. Kern, and H. Maurer, "Optimal control problems with delays in state and control variables subject to mixed control-state constraints," Optimal Control Applications and Methods, vol. 30, no. 4, pp. 341-365, 2009. 


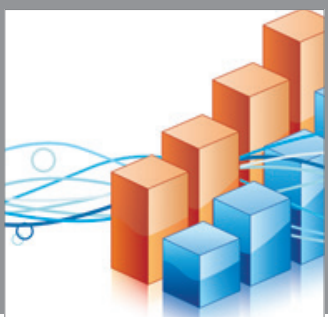

Advances in

Operations Research

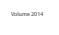

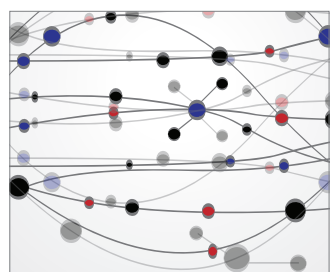

\section{The Scientific} World Journal
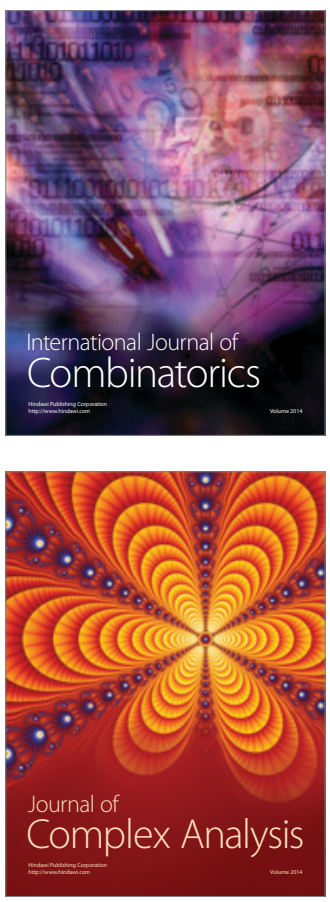

International Journal of

Mathematics and

Mathematical

Sciences
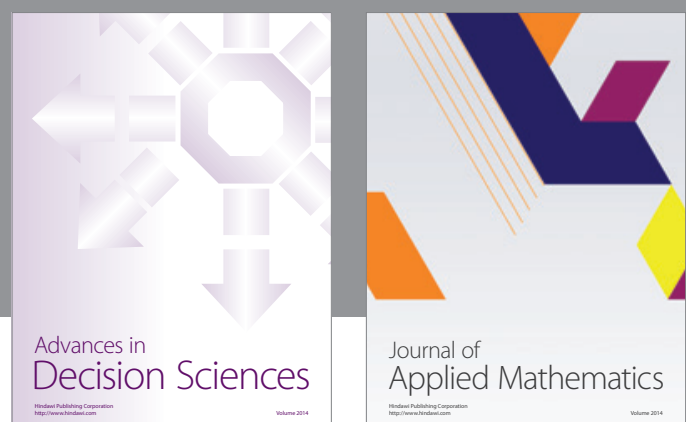

Journal of

Applied Mathematics
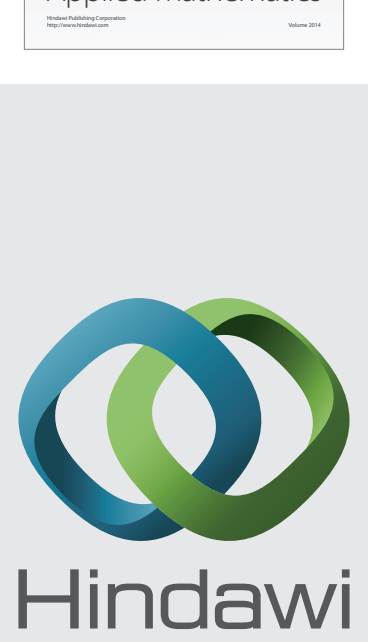

Submit your manuscripts at http://www.hindawi.com
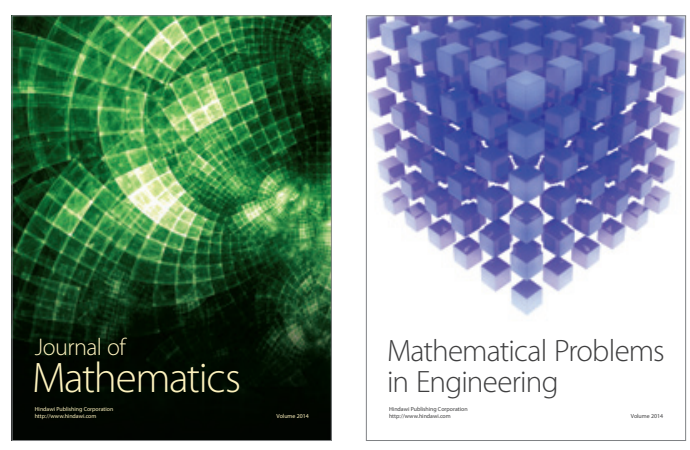

Mathematical Problems in Engineering
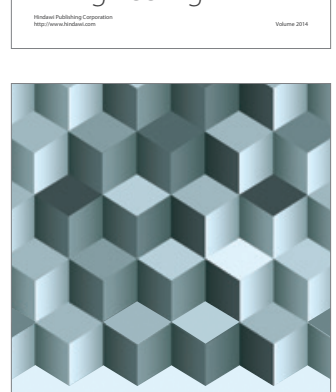

Journal of

Function Spaces
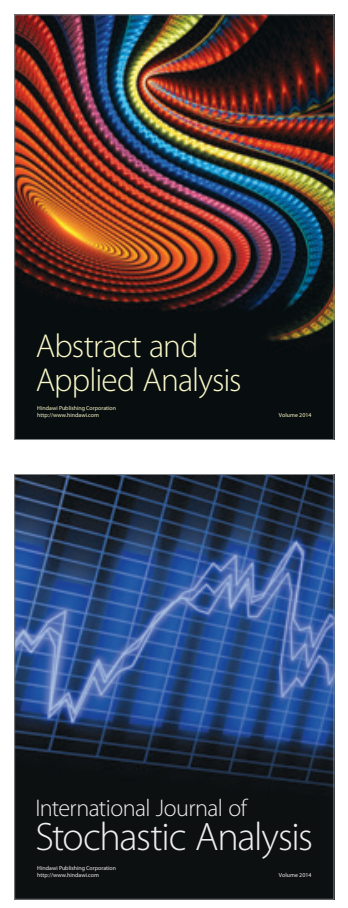

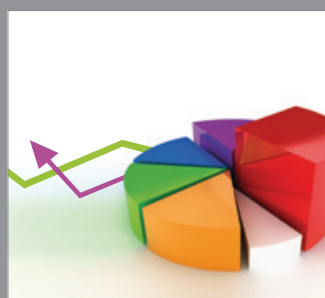

ournal of

Probability and Statistics

Promensencen
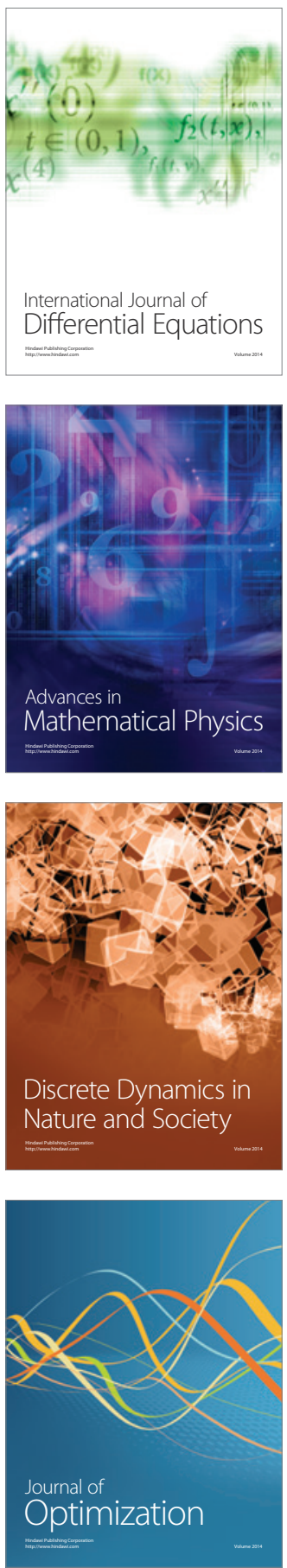